\title{
A REESCRIÇÃO DO RELATO DO GÊNESIS PELO PATRIARCADO COMO FORMA DE LIQUIDAR O MATRIARCADO
}

\author{
Leonardo Boff*
}

Não é tarefa fácil rastrear os passos que possibilitaram a liquidação do matriarcado e o triunfo do patriarcado, há 10-12 mil anos. O clássico livro sobre o matriarcado do jurista e antropólogo suíço Johan Jakob Bachofen (1815-1887) com seu livro Das Mutterrecht (1861), tentou traçar as etapas dessa verdadeira revolução.

Este livro, extremamente rigoroso e rico em dados históricos, antropológicos e jurídicos, influenciou todo o debate sobre o matriarcado e o feminismo posterior. Sustenta a tese de que no processo civilizatório foram as mulheres e as mãe as principais produtoras de cultura.

Essa visão foi aprofundada a partir de 1986 quando se criou a Internationale Akademie HAGIA, dedicada à pesquisa crítica e às experiências do matriarcado. A fundadora Heide Göttner-Abendroht (1988; 1991) resumiu as pesquisas em dois volumes Das Matriarcat I e II. Com Elizabeth Moltmann-Wendel (1991) levou avante a pesquisa com o livro: Frau und Man: alte Rolle-neue Wege (3). Importante neste contexto é o livro de Monica Sjöö e Barbara Mor (1991), The Great Cosmic Mother: Redescovering the Religion and the Earth.

Estes estudos entre outros mostraram que as grandes culturas, há cerca de 20 mil anos até o advento do patriarcado por volta de 10 mil anos eram matriarcais, não só na bacia do Mediterrâneo mas, com

* Ecoteólogo da libertação, filósofo e escritor. Foi professor de teologia no Instituto Franciscano de Teologia de Petrópolis, professor de ética e ecologia filosófica na UERJ e professor visitante em várias universidades estrangeiras, como Lisboa, Basel, Heidelberg e outras. Escreveu três livros sobre o tema do feminino: $O$ rosto materno de Deus (2012), O feminino e o Espírito Santo (2014) e, em co-autoria com Rose Marie Muraro, Feminino/Masculino: uma nova consciência para o encontro das diferenças (2010). É portador do Prêmio Alternativo da Paz de 2001 pelo Parlamento sueco e é dr.h.c; multi. 
lugares e datas diferentes, por toda a Terra. Conheciam os processos produtivos das sementes e os tempos da natureza. Prevaleciam as grandes deusas, fato testemunhado um pouco por todas partes. Elas eram veneradamente respeitadas e inspiraram as organizações sociais, marcadas pela cooperação e pela reverência em face da vida e dos seus mistérios.

As mulheres detinham a hegemonia política: mediavam e solucionavam eventuais conflitos e organizavam, com sentido de grande integração e paz, as sociedades. A natureza não era vista como algo a ser conquistado, mas como uma totalidade da qual se sentiam parte e parcela e com a qual viviam em harmonia, na veneração e no respeito.

As instituições do matriarcado, caracterizadas por grande força integradora, foram tão significativas que se transformaram em arquétipos do inconsciente coletivo e em valores que, como tais, deixaram incisões na memória genética humana até os dias de hoje. A própria linguagem estaria associada ao trabalho civilizador das mulheres. Como afirmam Monica Sjöö e Barbara Mor (1991, p. 38): “Faz sentido que as mulheres que deram à luz a vida mediante a boca sexual ou vaginal, tenham também dado à luz à linguagem humana através da boca facial e social".

Por volta dos anos entre 8-10 mil aos, variando as datas segundo as diferentes regiões, o mundo começou a pertence aos homens. Fundou-se o patriarcado, base do machismo e da ditadura cultural do masculinismo.

São obscuras as razões dessa passagem que demorou quase mil anos para se impor e perdurar até os dias atuais, não obstante o grande movimento mundial do feminismo e do ecofeminismo e da luta histórica pela igualdade de direitos de gênero. Provavelmente a vontade de dominar a natureza, levou os homens a subjugar a mulher, identificada com a natureza pelo fato de estar mais próxima dos processos naturais da gestação e do cuidado da vida.

O grave é que os homens conseguiram "naturalizar" esta dominação e introjetá-la na maioria das mulheres. É conhecida a crítica radical que Simone de Beauvor fez desse acontecimento histórico-cultural em seu famoso livro O segundo sexo de 1949.

Houve também um avanço expressivo na análise literária e antropológica desta passagem, utilizando os métodos modernos da hermenêutica, estruturalismo e da psicologia do profundo à lá Carl Gustav Jung. Decifraram os rastos dessa luta de gênero. 
Queremos ilustrar esse processo mediante a forma como foi relido o pecado de Adão e Eva. Aí se nos revela o trabalho de desmonte, diria feroz, do matriarcado pelo patriarcado.

Essa releitura foi apresentada por duas conhecidas teólogas feministas, Riane Eisler (1995) num instigando livro e de Françoise Gange (1997). Após cuidadosas análises do atual texto patriarcal do Gênesis, identificaram um sub-texto matriarcal. Este foi relido a partir da ótica patriarcal dominante e habilmente transformado numa justificativa divina da prevalência do homem sobre a mulher.

Segundo estas duas autoras, se realizou uma espécie de processo de culpabilização das mulheres no esforço de consolidar o domínio patriarcal e rebaixar o valor da mulher. Os ritos e símbolos sagrados do matriarcado foram diabolizados e retroprojetados às origens na forma de um relato primordial, com a intenção de apagar totalmente os traços do relato feminino anterior.

O atual relato do pecado das origens, acontecido no paraíso terrenal, coloca em xeque quatro símbolos fundamentais da religião das grandes deusas-mães.

O primeiro símbolo a ser atacado foi a própria mulher $(\mathrm{Gn} .3,16)$ que na cultura matriarcal representava o sexo sagrado, gerador de vida. Como tal ela simbolizava a Grande-Mãe, a Suprema Divindade.

Em segundo lugar, se desconstruiu o símbolo da serpente, considerado o atributo principal da Deusa-Mãe. Ela representava a sabedoria divina que se renovava sempre como a pele da serpente.

Em terceiro lugar, desfigurou-se a árvore da vida, sempre tida como um dos símbolos principais da vida. Ligando o céu com a terra, a árvore continuamente renova a vida, como fruto melhor da divindade e do universo. O Gênesis 3,6 diz explicitamente que "a árvore era boa para se comer, uma alegria para os olhos e desejável para se agir com sabedoria"

Em quarto lugar, destruiu-se a relação homem-mulher que originariamente constituía o coração da experiência do sagrado. A sexualidade era sagrada pois possibilitava o acesso ao êxtase e ao saber místico.

Ora, o que fez o atual relato do pecado das origens? Inverteu totalmente o sentido profundo e verdadeiro desses símbolos. Dessacralizou-os, diabolizou-os e os transformou de bênção em maldição. 
A mulher será eternamente maldita, feita um ser inferior. $O$ texto bíblico diz explicitamente que "o homem a dominará" (Gen. 3,16). O poder da mulher de dar a vida foi transformado numa maldição: "Multiplicarei o sofrimento da gravidez" (Gn. 3,16). Como se depreende, a inversão foi total e de grande perversidade.

A serpente é maldita $(G n .3,14)$ e feita símbolo do demônio tentador. O símbolo principal da mulher foi transformado em seu inimigo figadal: "Porei inimizade entre ti e a mulher... Tu lhe ferirás o calcanhar" (Gn. 3,15).

A árvore da vida e da sabedoria vem sob o signo do interdito (Gn. 3,3 ). Antes, na cultura matriarcal, comer da árvore da vida era se imbuir de sabedoria. Agora comer dela significa um perigo mortal (Gn. 3, 3), anunciado por Deus mesmo. O cristianismo posterior substituirá a árvore da vida pelo lenho morto da cruz, símbolo do sofrimento redentor de Cristo.

O amor sagrado entre o homem e a mulher vem distorcido: "Entre dores darás à luz aos filhos; a paixão arrastar-te-á para o marido e ele te dominará" (Gn. 3,16). A partir de então se tornou impossível uma leitura positiva da sexualidade, do corpo e da feminilidade.

Aqui se operou um desconstrução total do relato anterior, feminino e sacral. Apresentou-se outro relato das origens que vai determinar todas as significações posteriores. Todos somos, bem ou mal, reféns do relato adâmico, antifeminista e culpabilizador. A coleção de preconceitos sobre a mulher, a partir da leitura patriarcal, foi sumariado por Tama Start e Claudia Sant'Anna Martins (1994) num livro cheio de ditos preconceituosos.

O trabalho das teólogas, além de seu valor hermenêutico, pretende ser libertador: mostrar o caráter construído do atual relato dominante, centrado sobre a dominação, o pecado e a morte; e propor uma alternativa mais originária e positiva na qual aparece uma relação nova com o homem e a mulher, com a vida, com o poder, com o sagrado e com a sexualidade.

Essa interpretação não visa repristinar uma situação passada, mas, ao resgatar o matriarcado, cuja existência é cientificamente assegurada, encontrar um ponto de equilíbrio maior entre os valores masculinos e femininos para os dias atuais. 
Estamos assistindo a uma mudança de paradigma nas relações masculino/feminino. Esta mudança deve ser consolidada mediante um pensamento profundo e integrador que possibilite uma felicidade pessoal e coletiva maior do que aquela debilmente alcançada sob o regime patriarcal.

Mas isso só se consegue descontruindo relatos que destroem a harmonia masculino/feminino e construindo novos símbolos que inspirem práticas civilizatórias e humanizadoras para os dois sexos. É o que as feministas, antropólogas, filósofas e teólogas e outras estão fazendo com expressiva criatividade.

Este foi o propósito do livro que Rose Marie Muraro e Leonardo Boff (2010), depois de anos de pesquisa sobre a questão do feminino/ masculino, tentamos esboçar no livro Feminino e Masculino: uma nova consciência para o encontro das diferenças.

$* * *$

Não quero encerrar este pequeno trabalho dedicado à amiga Maria José Rosado Nunes sem me referir a um episódio, ocorrido na nossa parte do mundo, acerca do fim trágico de uma cultura matriarcal do Haiti nos começos do século XVI. É narrado pela escritora Edwige Danticat (2010). É negra e imigrante, nasceu no Haiti e viveu no país até o início de sua adolescência. Depois conseguiu entrar nos USA e se tornou uma premiada escritora. Ela é autora do clássico Adeus, Haiti.

No tempo que teve que ficar no Haiti, esperando a licença para imigrar nos USA, ouviu muitas histórias contadas pela avó e os tios. Ele ouviu uma história que ficou na memória do povo até os dias de hoje: o trágico destino de Anacaona.

Era a rainha da tribo dos Arauak, poeta, pintora e dançarina. A cultura era matriarcal. Ela governava a parte oeste da ilha, chamada de Ayiti que na língua indígena original significava "terra de grandeza" pela exuberância de sua paisagem verde.

Todos viviam tranquilos naquela parte até que, por mar, chegaram, traiçoeiros, os espanhóis sedentos de riqueza e de ouro. Saqueavam e matavam em função de sua ganância. Assim que logo prenderam a rainha Anacaona. Foi estuprada diante de todos e morta. 
Toda aldeia foi saqueada e destruída. Ainda no século XVI com a presença dos espanhóis, todos os indígenas morreram por causa das doenças dos brancos ou foram simplesmente exterminados. Para substitui-los foram trazidos para serem escravos, milhares de africanos. Mesmo assim, até hoje muitas crianças negras recebem o nome de Anacaona em lembrança tanto do esplendor do passado quanto da continuada agonia do presente.

Edwidge Danticat narra o que ouviu de sua avó, dos padecimentos da escravidão mas também de sua resistência e de sua fé. Os submetidos à perversa escravidão, acreditavam que quando morressem, seus espíritos retornariam à África, à uma terra pacífica de nome Ginen, habitada por deuses e deusas benfazejos. Assim conferiam um sentido maior à sua desumanização e lhes abria a porta para uma vida de liberdade e de bem-aventurança.

Curiosamente desenvolveram, no meio das maiores adversidades, uma visão encantada da vida. Segundo esta visão, para eles, o que conta, de verdade, na vida é estar vivo e sobreviver. Foi o que mais impressionou a autora. A avó contava que mulheres como ela, quando se encontravam nos caminhos, ou voltavam cansadas e empoeiradas das roças se cumprimentavam com esta expressão: "nou lèd, nou la" que quer dizer: "somos feias mas estamos aqui".

Comenta Edwidge:

"Talvez esse ditado não agrade à sensibilidade estética de algumas mulheres. Mas este ditado é para as mulheres pobres haitianas, como a minha avó, mais caro que a manutenção da beleza real ou produzida. O que vale a pena ser celebrado é o fato de que estamos aqui, de que apesar de todos os sofrimentos, nós existimos. A essência da vida é a sobrevivência, é poder continuar a viver" (Edwige DANTICAT, 2010, p. 58).

Edwidge conclui seu relato clamando:

"Nós somos filhas de Anacaona. Nós envergamos mas não quebramos. Não somos atraentes, mas ainda assim resistimos. De vez em quando devemos gritar o mais distante que o vento puder levar nossas vozes: Nou lèd, nou la! Somos feias mas estamos aqui" (Edwige DANTICAT, 2010, p. 65). 
O que nos ensina esta comovente saga haitiana? É a constatação do fato de que tantos e tantas na vida, nas comunidades das periferias de nossas cidades brasileiras, passam por tragédias absurdas. Sofrem a mais não poder ao ver sua filhinha sendo morta por uma bala perdida da polícia ou de traficantes.

Derramadas todas as lágrimas, suportando o descaso da justiça, não lhes resta senão dizer: "somos vítimas e somos pobres, mas estamos aqui! A vida dura e lutada deve continuar". E vão em frente, "sem ninguém com quem contar", como diz a canção.

\section{BIBLIOGRAFIA}

ABENDROHT, Heide Göttner. Das Matriarcat I. Stuttgart: Verlag Kolhammer, 1988.

ABENDROHT, Heide Göttner. Das Matriarcat II. Stuttgart: Verlag Kolhammer, 1991. ABENDROHT, Heide Göttner; MOLTMANN-WENDEL, Elizabeth. Frau und Man: alte Rolle-neue Wege. Düsseldorf: Verlag, Patmos 1991.

BACHOFEN, Johan Jakob. Das Mutterecht, Stuttgart: Verlag von Kraus und Hoffmann, 1861.

DANTICAT, Edwige. Adeus, Haiti. Rio de Janeiro: Agir, 2010.

EISLER, Riane. Sex, Myth and Politics of the Body. San Francisco: Harper San Francisco 1995.

GANGE, Françoise. Les dieux menteurs. Paris: Éditions Indigo-Côtes Femmes 1997.

MURARO, Rose Marie; BOFF, Leonardo. Feminino e Masculino: uma nova consciência para o encontro das diferenças. Rio Janeiro: Record, 2010.

SJÖÖ, Monica; MOR, Barbara. The Great Cosmic Mother: Rediscovering the Religion and the Earth. San Francisco: Harper San Francisco, 1991.

STARR, Tama; MARTINS, Claudia Sant'Anna. A voz do dono: cinco mil anos de machismo e misoginia. São Paulo: Ática, 1994. 